\title{
KONTRAK KERJA DAN KESEJAHTERAAN ABK NELAYAN PERSPEKTIF ETIKA BISNIS ISLAM DI SARANGMEDURO, JAWA TENGAH
}

\section{WORK CONTRACT AND WELFARE OF FISHING BOAT CREW FROM ISLAMIC BUSINESS ETHICS PERSPECTIVE IN SARANGMEDURO, CENTRAL JAVA}

\author{
Ani Fatmawati \\ Ekonomi Syariah FEBI UIN Sunan Ampel Surabaya Jl. Jend. A. Yani 117 Surabaya \\ Email: anifatmawati85@gmail.com
}

\section{Ana Toni Roby Candra Yudha}

Akademisi Ekonomi Syariah FEBI UIN Sunan Ampel Surabaya Jl. Jend. A. Yani 117 Surabaya Email: anatoniroby@uinsby.ac.id

\section{Hammis Syafaq}

Akademisi Ekonomi Syariah FEBI UIN Sunan Ampel Surabaya Jl. Jend. A. Yani 117 Surabaya Email: hammissyafaq@uinsby.ac.id

Keywords :
Work Contract, Welfare, Fishermen, Islamic Business Ethics

\begin{abstract}
Analysis of work contracts on the welfare of crew in fishermen sector from the Perspective of Islamic business ethics in Sarangmeduro Village is a study that aimed to answer questions about how the fishermen sector work contracts are implemented and how the welfare of the crew members is applied in Sarangmeduro Village. The methodology used was descriptive qualitative method with the type of case study research on the object. The result of this research is that the work contract conducted by fishermen in Sarangmeduro Village is a work contract system that has been implemented from generation to generation and is more likely to approach the muzaroah contract in profit sharing of maro or paroan. Based on the field of employment, the fishermen in Sarangmeduro Village live in prosperity. By the opening jobs provided by ship employers, they are facilitated in finding work. The residence that is inhabited every year has changed, which was originally made of woven bamboo, now most of them are built of bricks. The existence of a work contract implemented by fishermen can help to boost the economic condition of the fishermen in Sarangmeduro Village, which is always developing. The researcher recommend that fishermen make work inovation.
\end{abstract}

Kata kunci :

ABSTRAK

Kontrak Kerja, Kesejahteraan, Nelayan, Etika Bisnis Islam

Analisis Kontrak Kerja Terhadap Kesejahteraan ABK di Sektor Nelayan Perspektif Etika Bisnis Islam di Desa Sarangmeduro merupakan penelitian yang bertujuan untuk menjawab pertanyaan tentang bagaimana pelaksanaan kontrak kerja di sektor nelayan dan bagaimana kesejahteraan ABK terhadap kontrak kerja yang 


\begin{abstract}
diterapkan di Desa Sarangmeduro. Metodologi yang digunakan adalah metode kualitatif deskriptif dengan jenis penelitian studi kasus pada objek. Hasil penelitian yang diperoleh adalah kontrak kerja yang dilakukan oleh warga nelayan Desa Sarangmeduro merupakan sistem kontrak kerja yang sudah diterapkan secara turun temurun serta lebih cenderung mendekati akad muzaraah dalam pembagian hasil maro atau pun paroan. Berdasarkan bidang ketenagakerjaan, warga nelayan Desa Sarangmeduro hidup dengan sejahtera. Dengan terbukanya lapangan pekerjaan yang disediakan oleh para majikan kapal, warga Desa Sarangmeduro dimudahkan dalam mencari pekerjaan. Tempat tinggal yang ditempati setiap tahun terdapat perubahan, yang semula terbuat dari anyaman bambu, rata-rata sekarang dibangun dari batu bata. Adanya kontrak kerja yang diterapkan oleh warga nelayan ini bisa membantu untuk mendongkrak keadaan perekonomian warga nelayan Desa Sarangmeduro. Peneliti merekomendasikan agar warga nelayan diharapkan untuk melakukan inovasi kerja.
\end{abstract}

Diterima: 10 Oktober 2020; Direvisi: 26 November 2020; Disetujui: 29 November 2020; Tersedia online: 18 Desember 2020.

How to cite : Fatmawati, A., Yudha, A. T. R. C., Syafaq, H. (2020). Kontrak Kerja dan Kesejahteraan ABK Nelayan Perspektif Etika Bisnis Islam di Sarangmeduro, Jawa Tengah. NUKHBATUL 'ULUM: Jurnal Bidang Kajian Islam, 6 (2), 204-220. https://doi.org/10.36701/nukhbah.v6i2.240

\title{
PENDAHULUAN
}

Desa Sarangmeduro merupakan desa yang terletak di Kecamatan Sarang, Kabupaten Rembang, Jawa Tengah. Desa ini berbatasan dengan pintu masuk Provinsi Jawa Timur sedangkan di sebelah utara berbatasan dengan pantai utara, yang memiliki potensi alam laut melimpah. Dari pantai ini mayoritas masyarakat Desa Sarangmeduro mengais mata uang untuk memenuhi kebutuhan dengan bekerja sebagai nelayan ${ }^{1}$. Masyarakat nelayan di Desa Sarangmeduro selalu menjaga sinergi dan solidaritas kerja, serta memiliki beberapa keunikan dalam pekerjaan dan tingkat profesionalitas kinerjanya ${ }^{2}$. Di antaranya terdapat transaksi hutang piutang antara ABK (Anak Buah Kapal) dengan majikan kapal. Transaksi ini tidak ada pembukuan sebagai bukti, dan pembayaran hutang tersebut tidak dikenakan biaya tambahan (riba) serta waktu pengembalian hutang ini tidak dibatasi oleh waktu pengembalian, artinya ABK bisa melunasi hutang-hutangnya kapan pun dia mau dengan syarat, ABK harus tetap bekerja di kapal tersebut ${ }^{3}$.

${ }^{1}$ Ana Toni Roby Candra Yudha, "Profesionalisme Dosen Luar Biasa (DLB) Pada Era Milenial Di UIN Sunan Ampel Surabaya: Sebuah Studi Analisis Konten" 2, no. Manajemen SDM (2020): 77-86, http://jurnalfebi.uinsby.ac.id/index.php/MANOVA/article/view/247.

${ }^{2}$ Syarifudin, Nurlailah, and Ana Toni Roby Candra Yudha, "The Allocation of Tabarru' Fund Underwriting Surplus of Iplan Sharia Product in PT. Asuransi Jiwa Generali Indonesia," Jurnal Ekonomi Syariah Teori Dan Terapan 7, no. 9 (2020): 1804-17, https://doi.org/10.1017/CBO9781107415324.004.

${ }^{3}$ Atle Wehn Hegnes, "The Map and the Terroir: Adapting Geographical Boundaries for PDO and PGI in Norway," British Food Journal 121, no. 12 (2019): 3024-42. 
Kemudian tata cara pelaksanaan bagi hasil dari penjualan ikan yang telah ditangkap", yaitu dengan sistem 'maro' 5 atau bagi hasil yang mana masingmasing pihak yakni majikan kapal dengan anak buah kapal mendapat bagian 50\% dari hasil penjualan bersih (hasil penjualan yang sudah dikurangi perbekalan kapal di antaranya kebutuhan pokok ${ }^{6}$, solar, es batu, retribusi TPI sebesar 5\% dan biaya perawatan kapal), serta sistem maro ini dilakukan ketika hasil penangkapan ikan terjual minimal 50 juta. Sedangkan ketika nelayan dalam keadaan lain (sepi penangkapan ikan) sistem pembagian yang digunakan adalah sistem cacaran, yaitu ketika hasil jual penangkapan ikan tidak mencapai 50\% bagi majikan kapal atau hasil jual ikan tidak mencukupi untuk menutup biaya perbekalan kapal.

Ihwal pemberian upah/gaji kepada pekerja, maka terdapat hadis dari Nabi saw. yang berbunyi;

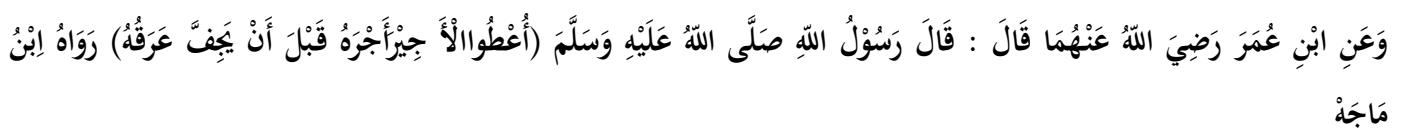

Artinya:

"Dari Ibnu Umar ra. berkata: Rasulullah saw. bersabda: "Berikanlah upah pekerja sebelum keringatnya kering”. (H.R. Ibnu Majah).

Dari hadis di atas terlihat jelas bahwa jika seorang juragan atau majikan yang mempekerjakan $\mathrm{ABK}$ atau buruh harus memberikan upah kepada pekerja sebelum keringatnya kering, artinya majikan akan segera membagi uang hasil penjualan ikan kepada para anak buah kapalnya dengan segara dan terbuka, dan hal tersebut selaras dengan prinsip profesionalitas kerja. Adanya Hadis ini adalah untuk meyakinkan para pekerja bahwa setelah mereka melakukan tugas pekerjaan ${ }^{7}$, mereka akan menerima imbalan atas apa yang telah dikerjakan yaitu pemberian upah dari seorang majikan.

Di antara masalah lain yang terjadi adalah kontrak kerja ABK kepada majikan kapal yaitu ketika ABK memiliki hutang kepada sang majikan, berarti ABK ini memiliki ikatan dalam bekerja sekaligus untuk mengukur kinerjanya,

\footnotetext{
${ }^{4}$ Firdausa Kumala Sari, Novita Safitri, and Wahyu Anggraini, "Persepsi, Sikap Dan Minat Pariwisata Halal Di Daerah Istimewa Yogyakarta," Ihtifaz: Journal of Islamic Economics, Finance, and Banking 2, no. 2 (2019): 137, https://doi.org/10.12928/ijiefb.v2i2.857.

${ }^{5}$ Perjanjian membagi dua hasil penjualan penangkapan ikan antara nelayan (penangkap ikan) dengan pemilik kapal, dengan mengeluarkan biaya operasional.

${ }^{6}$ Anisa Fadilah Zustika and Ana Toni Roby Candra Yudha, "Peer to Peer Lending System in Hifdul Maal Perspective: Evidence From He Fintech Company of Investree," Jurnal Ekonomi Syariah Teori Dan Terapan 7, no. 8 (2020): 1585-97, https://doi.org/10.20473/vol7iss20208pp1584-1597.

${ }^{7}$ Irham Zaki et al., "Implementation of Islamic Entrepreneurial Culture in Islamic Boarding Schools," International Journal of Innovation, Creativity and Change 11, no. 11 (2020): 452-69.
} 
sebagai jaminannya yaitu ABK yang melakukan transaksi utang piutang harus menetap bekerja di kapal majikan tersebut ${ }^{8}$. Ikatan tersebut bisa diselesaikan atau ABK bisa pindah bekerja di kapal lain apabila telah melunasi hutangnya kepada majikan kapal.

Dari beberapa keunikan fenomena tersebut penulis kemudian tertarik meneliti lebih mendalam tentang bagaimana cara bagi hasil dan kontrak kerja warga nelayan Desa Sarang jika dipandang dari segi Etika Bisnis Islam ${ }^{9}$, dan apakah bagi hasil yang diterapkan memunculkan dampak ekonomi bagi kesejahteraan masyarakat Desa Sarangmeduro yang bekerja sebagai nelayan dan berperan sebagai ABK. Untuk itu, penulis dalam melakukan penelitian ini mengambil sebuah judul "Analisis Kontrak Kerja Terhadap Kesejahteraan ABK di Sektor Nelayan Perspektif Etika Bisnis Islam di Desa Sarangmeduro, Kecamatan Sarang, Kabupaten Rembang”. Berdasarkan rumusan masalah yang dipaparkan sebelumnya, maka tujuan dari penelitian ini adalah untuk mengetahui kontrak kerja pada sektor nelayan di Desa Sarangmeduro Kecamatan Sarang Kabupaten Rembang, dan untuk mengetahui kesejahteraan terhadap kontrak kerja pada sektor nelayan di Desa Sarangmeduro Kecamatan Sarang Kabupaten Rembang.

Penelitian ini menggunakan metode kualitatif deskriptif dengan jenis penelitian studi kasus pada objek. Merupakan metode yang mengkaji dan menganalisis data yang didapatkan berupa data lisan atau pun tulisan serta tingkah laku manusia. Penelitian dengan metode ini tidak mengukur atau memperkirakan data menggunakan bilangan ${ }^{10}$. Menurut Strauss dan Corbin dalam buku berjudul, "Metode Kualitatif" karya Afrizal mengungkapkan bahwa metode penelitian kualitatif yaitu suatu jenis penelitian yang hasilnya tidak diperoleh dari hasil perhitungan data statistik melainkan dari tingkah laku manusia atau fenomena yang terjadi di lapangan ${ }^{11}$.

Metode penelitian kualitatif ${ }^{12}$ memiliki fungsi untuk mengutarakan sebuah mekanisme riil yang terjadi di lapangan. Penelitian ini fokus terhadap

${ }^{8}$ Sudirman Sudirman, "Implementasi Nilai Total Quality Management Dalam Pengelolaan Wakaf Di Dompet Dhuafa Dan Pondok Pesantren Tebuireng," Journal de Jure 4, no. 2 (2012): 171-86, https://doi.org/10.18860/j-fsh.v4i2.2986.

${ }^{9}$ Azwar Iskandar and Khaerul Aqbar, "Kedudukan Ilmu Ekonomi Islam Diantara Ilmu Ekonomi Dan Fikih Muamalah: Analisis Problematika Epistimologis," Nukhbatul 'Ulum: Jurnal Bidang Kajian Islam 5, no. 2 (2019): 88-105, https://doi.org/doi.org/10.36701/nukhbah.v5i2.77.

${ }^{10}$ Amalia Fadilah and Makhrus Makhrus, "Pengelolaan Dana Tabarru' Pada Asuransi Syariah Dan Relasinya Dengan Fatwa Dewan Syariah Nasional," Jurnal Hukum Ekonomi Syariah 2, no. 1 (2019): 87, https://doi.org/10.30595/jhes.v2i1.4416.

11 Salim and Syahrum, "Metode Penelitian Kualitatif" (Bandung: Citapustaka Medua, 2012)

${ }^{12}$ Leni Rohida, "Pengaruh Era Revolusi Industri 4.0 Terhadap Kompetensi Sumber Daya Manusia," Jurnal Manajemen Dan Bisnis Indonesia, 2018, https://doi.org/10.31843/jmbi.v6i1.187. 
analisis data yang didapat dari lapangan melalui wawancara, observasi, dan dokumentasi.

Adapun untuk mendapatkan data yang akurat, data diambil dari masyarakat nelayan di Desa Sarangmeduro. Sumber data yang digunakan dalam penelitian ini didapatkan dari sumber data primer melalui 3 orang Majikan Kapal di Desa Sarangmeduro, anak buah kapal yang terdiri dari 2 orang ABK biasa (belah tengah), 1 orang $\mathrm{ABK}$ tertentu (belah ngarep), 2 orang juru mudi (jeragan), 1 orang ABK yang bertugas sebagai penarik baling-baling (belah watang), 1 orang ABK yang bertugas sebagai koki, kepala TPI (Tempat Pelelangan Ikan) Desa Sarangmeduro, dan sekretaris Desa Sarangmeduro. Sedangkan untuk data sekunder, didapatkan dari narasumber lain seperti literatur yang mengandung penelitian ilmiah seperti jurnal ilmiah. Penulis juga melakukan analisis data di antaranya reduksi data, menafsirkan data, dan triangulasi ${ }^{13}$.

Berdasarkan hasil penelitian terdahulu dalam jurnal yang berjudul "Analisis Upah Sistem Bagi Hasil Anak Buah Kapal Pada Perahu Penangkapan Ikan di Kabupaten Lamongan (Studi Kasus Perahu Jenis Ijon-Ijon Payangan Pada Masyarakat Nelayan di Kelurahan Brondong dan Kelurahan Blimbing)". Hasil dari penelitian tersebut yaitu warga nelayan Kelurahan Brondong dan Kelurahan Blimbing menggunakan sistem upah bagi hasil (Profit-Sharing System). Sistem pengembalian (return) yang diterapkan adalah sistem bagi hasil ${ }^{14}$, bagi hasil yang didapatkan antara juragan kapal dengan anak buah kapal di kelurahan ini adalah $60 \%: 40 \%$. Persamaan dari jurnal ini dengan penelitian yang diteliti adalah pada membahas tentang sistem upah bagi hasil di sektor nelayan ${ }^{15}$. Perbedaan dari jurnal penelitian terletak pada kontrak kerja dan dampak penerapan dari kontrak kerja tersebut bagi kesejahteraan masyarakat Desa Sarangmeduro yang bekerja sebagai nelayan ABK.

Dari penelitian terdahulu yang berjudul "Wages Distribution System of Sailor in Sarang (John Rawls's Theory of Justice Perspective). Titik persamaan dari penelitian ini adalah sama-sama mengkaji tentang sistem upah nelayan di Sarang. Namun, terdapat perbedaan yaitu dalam penelitian tersebut menggunakan teori keadilan perspektif John Rawls, sedangkan dalam penelitian penulis menggunakan perspektif etika bisnis Islam serta memaparkan

${ }^{13}$ Dinna Miftakhul Jannah and Lucky Nugroho, "Strategi Meningkatkan Eksistensi Asuransi Syariah Di Indonesia,” Jurnal Maneksi 8, no. 1 (2019): 169-76.

${ }^{14}$ Muhamad Nafik Hadi Ryandono and Ahmad Ajib Ridlwan, "Solution for Islamic Banks Exploitation: A Criticism of Fixed-Yields Based Financing in Indonesia," Al-Uqud: Journal of Islamic Economics 4, no. 1 (2020): 48-68, https://doi.org/10.26740/al-uqud.v4n1.p48-68.

${ }^{15}$ Ahmad Heryawan, Akhmad Fauzi, and Aceng Hidayat, "Ekonomi Pertanian , Sumberdaya Daya dan Lingkungan ( Journal of Agriculture , Resource , and Environmental Economics ) Analisis Ekonomi dan Kebijakan Sumber Daya Alam," Analisis Ekonomi Dan Kebijakan Sumber Daya Alam Provinsi Jawa Barat 1, no. 3 (2014): 1-11. 
kesejahteraan masyarakat nelayan Desa Sarangmeduro terhadap kontrak kerja yang telah diterapkan.

\section{PEMBAHASAN}

\section{Letak Geografis}

Desa Sarangmeduro adalah salah satu desa yang masuk kedalam wilayah Kecamatan Sarang, Kabupaten Rembang, Jawa Tengah. Desa ini terletak dibagian paling utara berdekatan dengan Pantai Utara, yang memiliki potensi hasil alam laut melimpah. Dekatnya pantai utara dengan Desa Sarangmeduro memberikan mata pencaharian warga desa Sarangmeduro sebagai nelayan di laut pantai utara. Desa Sarangmeduro memiliki luas wilayah 32.60 Ha.

Desa ini dibatasi oleh Laut Jawa yang yang berada di sisi utara, sebelah selatan berdekatan dengan Desa Sendang Mulyo, sebelah timur berdampingan dengan Desa Bajing Meduro, dan sebelah barat berdekatan dengan Desa Kalipang. Secara administratif, Desa ini terdiri dari 9 Rukun Tetangga (RT) dan 2 Rukun Warga (RW).

Rekapitulasi jumlah penduduk Desa Sarangmeduro tercatat jumlah penduduk Desa Sarangmeduro adalah 3.603 jiwa yang terdiri dari 1.873 jiwa lakilaki dan 1.730 jiwa perempuan, dan jumlah penduduk yang masuk dalam kategori keluarga miskin sejumlah 532 KK dari 1030 KK penduduk Desa Sarangmeduro.

Desa Sarangmeduro termasuk desa dengan kepadatan penduduk yang cukup tinggi di wilayah Kecamatan Sarang. Mata pencaharian penduduk di desa ini mayoritas sebagai nelayan dan sebagian kecil lainnya bermata pencaharian sebagai Guru, PNS, Pedagang, Petani dan Wiraswasta.

\section{Aktivitas Perekonomian Warga Desa Sarangmeduro}

Sektor ekonomi yang mendasar di wilayah Desa Sarangmeduro adalah sektor nelayan, perdagangan, persewaan dan jasa. Desa Sarangmeduro menurut letak geografisnya, berbatasan langsung dengan Pantai Utara Jawa yang menyebabkan penduduk di desa ini memiliki aktivitas ekonomi mayoritas sebagai nelayan dan pedagang.

\section{Nelayan Desa Sarangmeduro}

Sistem kerjasama atau kontrak kerja antara majikan dengan ABK pada masyarakat nelayan umumnya berdasarkan adat kebiasaan wilayah setempat. Di dalam kapal yang dijalankan oleh orang nelayan terdapat beberapa bagian yang memiliki tugas dan tanggung jawab yang berbeda-beda ${ }^{16}$. Berdasarkan kapal nelayan yang ada di Desa Sarangmeduro terdapat dua bagian yaitu majikan dan

${ }^{16}$ Tariqullah Khan, "Venture Waqf in a Circular Economy," ISRA International Journal of Islamic Finance 11, no. 2 (2019): 187-205, https://doi.org/10.1108/IJIF-12-2018-0138. 
ABK. Sedangkan struktur pembagian pos kerja dapat digambarkan sebagaimana alur bagan berikut ini.

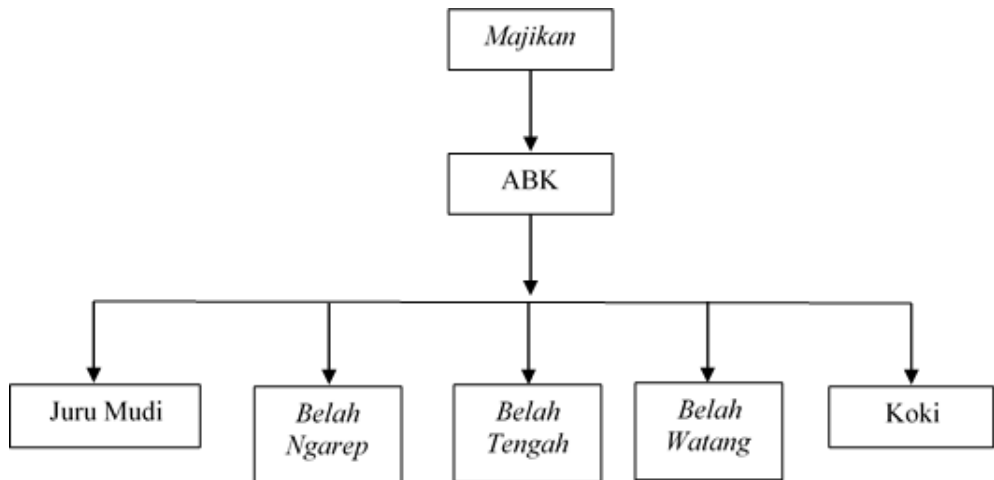

\section{Gambar 1. Struktur Tugas dan Posisi Pelaut di Desa Sarangmeduro}

Bersesuaian dengan Gambar 1 tentang struktur tugas dan posisi pelaut di Desa Sarangmeduro. Untuk itu, definisi dan tupoksi kerja dari masing-masing peran yaitu: (1) Majikan. Majikan adalah seorang pemilik kapal. Selain memiliki wewenang untuk penyedia modal, majikan juga mengurus dan memenuhi apa yang dibutuhkan kapal, serta mengatasi pembagian upah ${ }^{17}$; (2) ABK (anak buah kapal). ABK memiliki beberapa posisi dengan tugas dan tanggung jawab yang berbeda. Posisi dan tanggung jawab yang mereka miliki menentukan besar kecilnya nominal upah yang akan didapatkan.

Posisi tersebut di antaranya: (a) Juru mudi/juragan, yaitu sebutan dari seorang kapten; (b) Belah Ngarep, merupakan ABK yang memiliki tanggung jawab dibawah jeragan; (c) Belah Tengah (ABK biasa), merupakan ABK yang memiliki tanggung jawab yang cukup ringan; (d) ABK bagian koki atau juru masak, memiliki tugas untuk memelihara kebutuhan ABK dalam hal konsumsi keseharian ABK; (e) Belah Watang atau penarik baling-baling yang memiliki tugas sebagai penarik baling-baling ketika kapal berhenti, dan menurunkan baling-baling ketika kapal akan jalan.

\section{Kesepakatan Warga Nelayan}

Kesepakatan kerja yang diulas pada pembahasan artikel ini meliputi beberapa bagian dan disederhakanan menjadi sebuah skema. Bagian tersebut terdiri dari proses rekrutmen, pemberangkatan dan kesepakatan bagi hasil antara majikan kapal, juru mudi (kapal), dan anak buah kapal (ABK). Berikut skema yang dimaksud pada gambar 2. di bawah. Ketika semua perbekalan kapal yang akan dibawa sudah siap, dan memiliki ABK yang cukup untuk berangkat melaut,

${ }^{17}$ Asma Raies, "Islamic versus Conventional Fiscal Policy: The Effect of Zakat on Education and Employment," Academic Journal of Interdisciplinary Studies 9, no. 1 (2020): 2733, https://doi.org/10.36941/ajis-2020-0003. 
kemudian salah satu ABK akan memberitahu ABK yang lain bahwa kapal akan berangkat besok pagi. Ketika ABK setuju untuk bergabung dengan kapal, itulah yang disebut sebagai proses awal pelaksanaan ${ }^{18}$, perjanjian distribusi upah dan kontrak kerja untuk satu kali berangkat melaut.

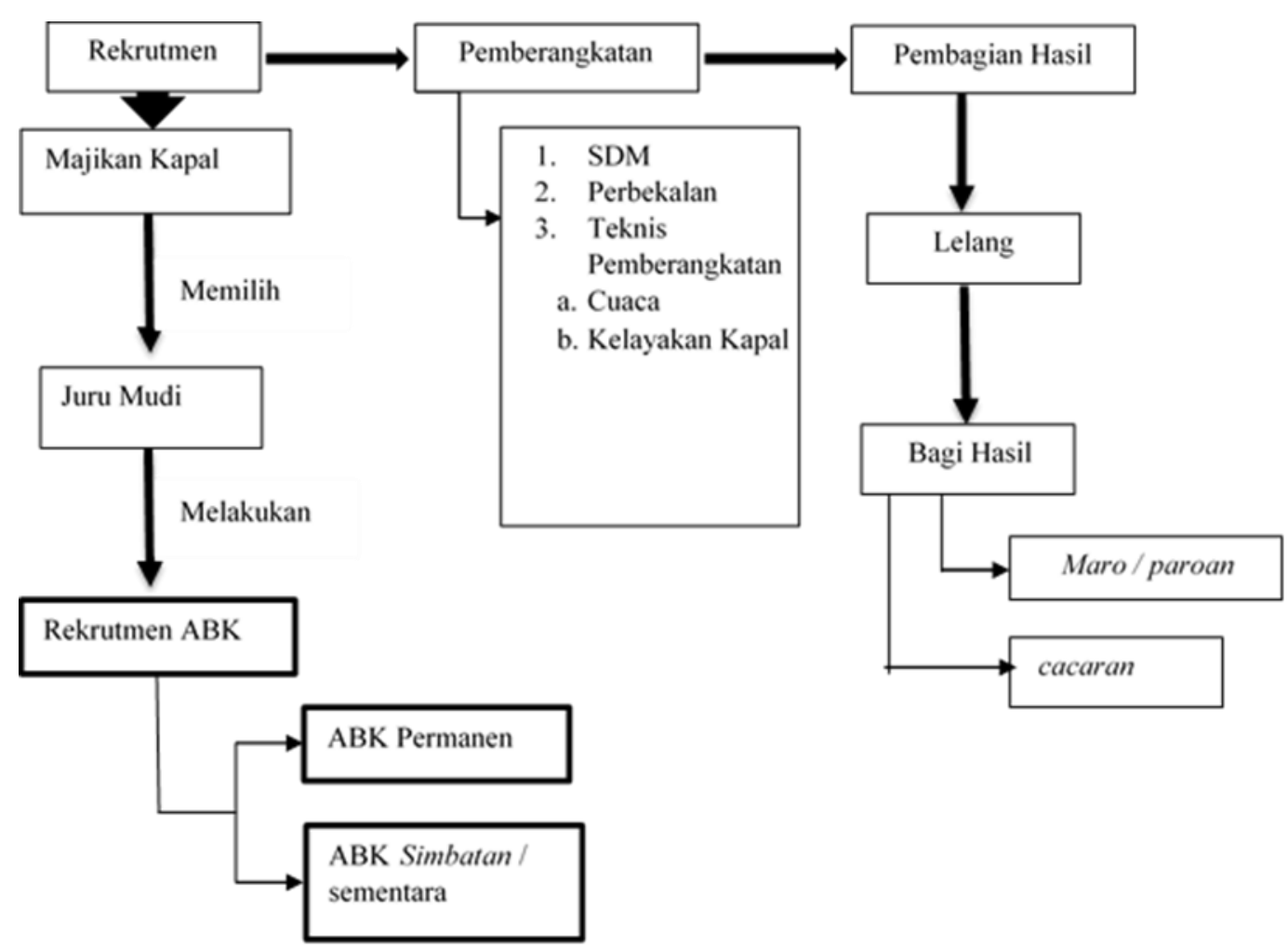

Gambar 2. Skema Kesepakatan Warga Nelayan

Oleh karena itu, hubungan menjadi jelas dan tidak kabur karena hasil perjanjian dan kontrak kerja telah diketahui dan didengar. Meskipun kesediaan ABK untuk berangkat melaut sekedar memakai kata-kata (abstrak), tetapi telah menjadi tanggung jawab yang harus dilakukan ${ }^{19}$. Jadi seorang ABK dikatakan melakukan awal perjanjian kontrak yaitu ketika salah satu ABK bersedia untuk ikut berangkat melaut. Hal ini karena sudah terpenuhi sifat kejelasan atau telah melakukan ijab ketika seorang ABK bersedia ikut melaut. Seperti sebuah pertemuan ijab yang dikemukakan oleh salah satu pihak kemudian muncul "kabul" dari pihak lain yang memunculkan akibat hukum pada objek akad"20.

\footnotetext{
${ }^{18}$ Iskandar and Aqbar, "Kedudukan Ilmu Ekonomi Islam Diantara Ilmu Ekonomi Dan Fikih Muamalah: Analisis Problematika Epistimologis."

${ }^{19}$ Mohamed Battour, Muhammad Khalilur Rahman, and Md Sohel Rana, "The Impact of PHTPS on Trip Quality, Trip Value, Satisfaction and Word of Mouth: Non-Muslim Tourists' Perspective," Journal of Islamic Marketing, 2019, https://doi.org/10.1108/JIMA-03-2019-0058.

${ }^{20}$ Akmalur Rijal, "Pengetahuan Konsumen Terhadap IB Hasanah Card Bank BNI Syariah Cabang Surabaya" 1, no. 1 (2018): 117-39.
} 
Kontrak kerja yang dilakukan oleh warga nelayan Desa Sarang sekilas mirip sekali dengan sistem muzaraah atau sistem kerjasama yang dilakukan oleh petani. Mulai dari pihak majikan kapal yang menyediakan kapalnya sebagai lapangan pekerjaan, dan pembagian upah yang dibagi secara rata kepada $A B K$ nya. Kontrak kerja nelayan ini pun jika mendapat keuntungan (kapal mendapat tangkapan ikan banyak atau Along) dapat dirasakan bersama, sebaliknya jika kapal dalam melaut mendapat tangkapan ikan sedikit (rugi) juga ditanggung bersama.

Di dalam dunia usaha tidak dipungkiri selalu dihiasi dengan mengisahkan terkait keuntungan dan kerugian. Sebuah kenyataan pahit dan manis yang pasti bersanding ${ }^{21}$. Terkadang pihak majikan kapal lebih memilih untuk mengalah untuk kesejahteraan ABK dan salah satu bentuk terima kasih majikan kepada anak buah kapalnya.

Dari gambaran penulis tentang skema kesepakatan kontrak kerja yang dilakukan oleh masyarakat nelayan Desa Sarangmeduro yaitu dengan sistem pihak majikan kapal menyediakan modal dengan bentuk menyediakan lapangan pekerjaan yakni kapal dengan peralatan menangkap ikan yang lengkap, serta perbekalan kapal yang juga ditanggungnya. Kemudian pihak ABK, mereka menyediakan tenaganya sebagai bentuk modal seorang ABK. Pendapatan melaut ini tidak bisa dipastikan, pun memiliki resiko yang besar. Pendapatan yang didapat akan dibagi rata antara majikan kapal dengan pihak ABK.

Apabila pendapatan yang didapat di luar ekspektasi, artinya pada keadaan Laib (ombak besar, ikan sulit didapat) maka pihak Majikan kapal akan membagi dengan sistem cacaran atau sistem ini lebih berpihak ke ABK. Tetapi pada dasarnya resiko ini pun ditanggung bersama, yakni Majikan Kapal dengan ABK. Nelayan Desa Sarangmeduro dalam menjalankan pembagian hasil dengan ABKnya umumnya menganut ajaran para leluhur mereka atau berdasarkan adat kebiasaan wilayah setempat.

Pada umumnya, pola bagi hasil adalah hasil dari sisa bersih setelah dikurangi biaya perbekalan makan, bahan bakar, dan retribusi TPI. Kemudian dibagi dua atau yang disebut sistem "Maro", yaitu 50\% untuk majikan dan 50\% untuk ABK. Selain sistem "Maro", warga nelayan Desa Sarangmeduro juga menggunakan sistem pembagian "Cacaran".

Sistem "Maro" terjadi ketika warga nelayan setiap berangkat bekerja melaut mereka mendapat hasil tangkapan ikan dengan harga jual yang tinggi dan ikan yang didapat juga banyak atau orang nelayan Desa Sarangmeduro

${ }^{21}$ Moh Khoiri Abdi and Novi Febriyanti, "Penyusunan Strategi Pemasaran Islam Dalam Berwirausaha Di Sektor Ekonomi Kreatif Pada Masa Pandemi Covid-19," El Qist - Journal of Islamic Economics and Business 10, no. 2 (2020): 160-79. 
menyebutnya "Along", atau memenuhi lobang ikan yang terdapat di dalam kapalnya.

Hasil penjualannya (borongan) pun mencapai lebih dari 50 juta atau bisa lebih. Sedangkan jika hasil tangkapan pada suatu pemberangkatan melaut tersebut sedikit atau dalam keadaan Laib (sepi penangkapan ikan), biasanya harga jual ikan yang didapat kurang dari 50 juta maka sistem pembagian yang digunakan adalah sistem "Cacaran" atau sepantasnya. Kondisi ini lantaran hasil penjualan ikan tidak mencukupi untuk membayar perbekalan kapal yang dibawanya, maka ABK juga ikut menanggung kerugiannya.

Seringkali jika melaut mendapat hasil tangkapan sedikit, maka majikan kapal tidak mendapat bagian hasil karena sedikitnya hasil yang mereka dapatkan. Di samping itu, majikan juga menjaga ABK-nya dengan mengalah atas pendapatan yang didapat agar ABK tidak berpindah ke kapal lain. Dalam hal ini, penentuan upah kerja dalam bisnis Islam adalah Islam tidak memberi batasan atau tidak terdapat ketentuan secara rinci sebagai tekstualnya. Akan tetapi di dalam Al- Qur'an terdapat salah satu ayat yang berkaitan dengan penentuan upah kerja yaitu pada Q.s. AnNahl ayat 90., yang berbunyi,

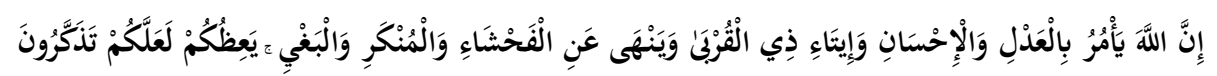

Terjemahnya:

"Allah memerintahkan berbuat adil, melakukan kebaikan dan dermawan terhadap kerabat. Dan Ia melarang perbuatan keji, kemungkaran, dan penindasan. Ia mengingatkan kamu supaya mengambil pelajaran" 22.

Dari ayat di atas dapat diambil beberapa pelajaran terkait perjanjian kerja, bahwa Allah telah memerintahkan kepada para majikan atau pemberi kerja untuk berbuat adil, menjalankan kebaikan serta dermawan terhadap anak buahnya. Istilah "kerabat" pada ayat 90 surat An-Nahl dapat diartikan sebagai "tenaga kerja", karena anak buah atau pekerja sudah dianggap dalam bagian dari perusahaan, dan jika bukan jerih payah yang dihasilkan oleh pekerja, tidak akan mungkin usaha seorang majikan akan sukses ${ }^{23}$.

Dari kerjasama kontrak kerja yang dilakukan oleh majikan kapal dengan anak buah kapal (ABK), masing-masing pihak akan menghasilkan keuntungan dan imbasnya juga bisa dirasakan oleh warga nelayan yang apabila tidak memiliki kapal atau belum memiliki pekerjaan tetapi mereka memiliki kemampuan untuk bekerja sebagai nelayan buruh atau ABK. Hikmah yang dapat

${ }^{22}$ Departemen Agama RI Al-Qur'an dan Terjemahnya special for women, (SYGMA),

${ }^{23}$ Chairuman Pasaribu dan Suhrawardi K. Lubis, Hukum Perjanjian Dalam Islam (Jakarta: Sinar Grafika Offset, 2004), hal: 157 
diambil dari sistem kontrak kerja muzaraah ${ }^{24}$ yang diterapkan oleh warga nelayan Desa Sarangmeduro ini di antaranya adalah: (1) Terciptanya sistem kerja sama yang saling menguntungkan untuk kedua belah pihak; (2) Kesejahteraan masyarakat bisa meningkat; (3) Teratasinya kemiskinan; dan (4) Memberikan lapangan pekerjaan, seperti halnya masyarakat nelayan yang tidak memiliki kapal sebagai fasilitas mereka untuk menangkap ikan tetapi mereka memiliki kemampuan untuk melaut.

Dari uraian praktik di atas yang dilakukan oleh warga nelayan Desa Sarangmeduro, jika ditinjau dari perspektif etika bisnis Islam, kontrak kerja yang telah diaplikasikan oleh warga nelayan Desa Sarangmeduro telah memenuhi prinsip dasar dari etika bisnis Islam ${ }^{25}$, di antaranya:

Prinsip Kesatuan (Tauhid/Unity). Yaitu dengan mengutamakan aspek religius yang di kaitkan dalam aktivitas perekonomian, sehingga didalam melakukan kegiatan berbisnis tidak melakukan bentuk penyimpangan dari segala ketentuanNya. Dalam hal ini, praktik pembagian hasil yang dilakukan oleh nelayan Desa Sarangmeduro sesuai dengan prinsip etika bisnis islam. Seperti ketika nelayan mendapat hasil tangkapan banyak, mereka akan membagi dua bagian atau dengan sistem "maro". Sedangkan jika hasil tangkapan sedikit, majikan akan lebih memilih untuk mengalah untuk kesejahteraan ABK.

Prinsip Keseimbangan (Keadilan/Equilibrium). Yaitu terwujudnya suatu aktivitas ekonomi di mana antara kedua belah pihak (majikan dan anak buah kapal) tidak ada yang dirugikan. Kondisi praktik bagi hasil yang terjadi pada warga nelayan Desa Sarangmeduro dianggap cukup berlaku adil dalam kerjasama, karena tidak ada yang merasa dirugikan. Mendapat penghasilan banyak atau pun tangkapan sedikit akan dirasakan bersama-sama, baik itu pihak ABK maupun majikan kapal.

Prinsip Kehendak Bebas (Ikhtiar/Free Will). Yaitu seperti halnya di dalam kontrak kerja nelayan Desa Sarangmeduro dalam melakukan pembagian hasil jual tangkapan ikan harus sesuai dengan kesepaktan bersama, dan dilakukan secara terbuka tanpa merugikan salah satu pihak.

Prinsip Pertanggungjawaban (Responsibility). Dalam dunia nelayan, perihal akan sebuah tanggung jawab pasti diberlakukan. Setelah melakukan aktivitas ekonomi dengan macam bentuk kebebasan, semuanya perlu akan adanya pertanggungjawaban dari berbagai pihak atas apa yang telah dilakukan.

${ }^{24}$ Muzara'ah menurut istilah merupakan sistem kerjasama dalam pengolahan pertanian antara pihak pemilik tanah dan pihak penggarap dengan menggunakan perjanjian bagi hasil yang didapatkan dari kesepakatan bersama, pada umumnya menggunakan paroan sawah atau fifty-fifty untuk pemilik sawah dan penggarap. in Norway."

${ }^{25}$ Hegnes, "The Map and the Terroir: Adapting Geographical Boundaries for PDO and PGI 
Misalnya, kapal akan berangkat melaut pasti terdapat bagian yang bertugas mempertanggungjawabkan memenuhi kebutuhan kapal yaitu majikan kapal, begitu pun sebaliknya, ABK juga akan bertanggung jawab sepenuhnya dengan tenaga yang mereka miliki dalam bekerja, menjaga dan memanfaatkan fasilitas yang disediakan oleh majikan dengan sebaik-baiknya.

Prinsip Ihsan (benevolence). Prinsip ini adalah dengan melakukan kegiatan positif yang memiliki tujuan memberi manfaat antar sesama. Dalam prinsip ihsan, terdapat perilaku yang sangat mempengaruhi untuk terciptanya prinsip ihsan dalam suatu bisnis, kemurahan hati (leniency) yaitu antara majikan kapal dengan ABK harus saling tolong menolong, motif pelayanan (service motive), di mana setelah majikan mempersiapkan kebutuhan untuk pemberangkatan kapal maka ABK tentunya akan melaksanakan pekerjaan dengan sebaik mungkin. Begitu pun sebaliknya antara ABK dengan majikan, serta aspek religius yang dikaitkan dengan aktivitas ekonomi yang nantinya akan menjadikannya sebagai sebuah prioritas.

Selain itu, kontrak kerja tersebut lebih cenderung mendekati pada akad muzaraah. Meskipun penggunaan akad muzaraah untuk para petani. Jika diteliti lebih mendalam, kontrak kerja yang dilakukan oleh nelayan Desa Sarangmeduro jika di padu-padankan, maka terdapat kesamaan dengan kontrak kerja petani yakni menggunakan akad muzaraah. Seperti yang dikemukakan ulama Hanabilah, beliau menyatakan bahwa muzaraah merupakan kontrak kerja yang dilakukan petani, di mana pemilik tanah menyerahkan tanahnya kepada pihak pengelola atau orang yang bercocok tanam, dan hasil dari tanaman tersebut akan dibagi antara kedua belah pihak.

Jika disamakan dengan profesi nelayan, pemilik tanah pada sistem muzaraah seperti diposisi majikan kapal. Mereka sama-sama sebagai penyedia modal dengan bentuk penyedia lapangan pekerjaan. Pihak petani menyediakan lahan tanahnya untuk digarap oleh pengelola sawahnya atau buruh tani, sedangkan pihak nelayan (majikan kapal) yang menyediakan kapal beserta peralatan lengkap untuk dikerjakan oleh anak buah kapalnya.

Menurut Salim dalam bukunya yang berjudul Perkembangan Hukum Di Indonesia ${ }^{26}$ menuturkan bahwa pengertian kontrak kerja merupakan suatu bentuk perjanjian yang dilakukan antara pekerja atau pegawai dan pengusaha baik dilakukan secara lisan atau pun secara tertulis, untuk waktu tertentu atau pun waktu tidak tertentu yang di dalamnya terdapat ketentuan syarat-syarat kerja, hak, dan kewajiban. Wujud dari perjanjian kerja yang dilakukan yakni rangkaian ucapan yang di dalamnya berisikan janji atau kesediaan atas apa yang telah

${ }^{26}$ Naila Rizki Salisa, Ida Nur Aeni, and Ahmad Abdul Chamid, "Analisis Faktor-Faktor Penerimaan Penggunaan Sistem Keuangan Desa: Pendekatan TAM Dan TPB," Ekonomi Dan Bisnis 6, no. 1 (2019): 34, https://doi.org/10.35590/jeb.v6i1.829. 
diucapkan atau pun ditulis. Menurut pandangan Islam, perjanjian kerja ikut termasuk ke dalam golongan perjanjian sewa-menyewa (Al-Ijārah), Ijārah A yān yaitu sewa-menyewa tenaga kerja manusia untuk menjalankan pekerjaan.

Warga nelayan Desa Sarangmeduro secara tidak sadar, mereka selama ini telah menerapkan kaidah kaidah Islam dalam hal melakukan sebuah pekerjaan. Seperti sebelum kontrak kerja nelayan, antara majikan kapal dengan ABK berlangsung, tidak disadari mereka telah melakukan akad terlebih dahulu.

Hal ini terbukti ketika penulis mengetahui alur kontrak kerja orang nelayan di Desa Sarangmeduro, yakni pada waktu pemberangkatan kapal. ABK yang bekerja di kapal bertugas memberi tahu kepada ABK yang lain bahwa kapal akan berangkat besok pagi, dan ketika ABK setuju untuk bergabung dengan kapal, itulah yang disebut sebagai proses awal perjanjian kontrak kerja yang dilakukan oleh nelayan Desa Sarangmeduro.

Dari ini bisa kita dilihat hubungan sebuah kerja sama akan lebih jelas dan tidak kabur karena hasil perjanjian dibuktikan dengan bersedianya ABK ikut bergabung untuk berangkat melaut pada esok harinya, dan kontrak kerja pun telah diketahui dan didengar secara jelas. Meskipun pernyataan kesediaan ABK untuk ikut bergabung dalam melaut hanya sekedar pernyataan secara lisan atau menggunakan kata-kata (abstrak), tetapi pernyataan tersebut telah berubah menjadi sebuah tanggung jawab yang harus dipenuhi oleh anak buah kapal.

Sebuah akad perjanjian ini bisa terjadi karena sudah terpenuhi sifat kejelasan atau telah melakukan ijab yang dibuktikan seorang ABK untuk bersedia ikut melaut. Seperti sebuah pertemuan ijab yang dikemukakan oleh salah satu pihak kemudian muncul "kabul" dari pihak lain yang memunculkan akibat hukum pada objek akad.

Harun juga menjelaskan bahwa makna dari istilah akad itu sendiri adalah pengikatan antara ijab (penawaran) yaitu ada pihak melakukan penawaran, dengan "kabul" (penerimaan) yakni terdapat pihak yang menerima dari sebuah penawaran tersebut, menurut syara' telah dibenarkan yang kemudian memunculkan keridaan (kerelaan) kedua belah pihak sehingga memiliki keterkaitan hukum tertentu.

\section{Kesejahteraan ABK dengan Kontrak Kerja}

Aliyah Farwah dalam jurnalnya yang berjudul "Faktor Sosial Terhadap Kesejahteraan Islam Keluarga Muslim di Kota Surabaya" mengemukakan bahwasanya kesejahteraan tidak mesti diukur dari sebuah pendapatan yang didapat $^{27}$. Akan tetapi, sejahtera tidak harus diperuntukkan bagi suatu masyarakat atau kelompok yang memiliki pendapatan yang konsisten. Istilah

${ }^{27}$ Aliyah Farwah, "Faktor Sosial Terhadap Kesejahteraan Islami Keluarga Muslim Di Kota Surabaya," Jurnal Ekonomi Dan Bisnis Airlangga (JEBA) 23, no. 2 (2013): 154-63. 
sejahtera ini dapat berubah-ubah, sebab tolok ukur yang digunakan untuk sebuah keluarga bisa dikatakan sebagai keluarga yang sejahtera dan tidak sejahtera seringkali para ahli ekonomi berbeda pendapat. Keluarga yang memiliki pendapatan ekonomi tinggi dengan setiap keperluannya terpenuhi bisa saja disebut sebagai keluarga sejahtera.

Namun, disamping itu, terdapat keluarga yang kurang berkecukupan dengan semua keperluannya yang belum bisa tercukupi terkadang justru lebih bisa merasakan arti dari kata sejahtera itu sendiri, karena mereka tidak memiliki tanggungan seperti yang dimiliki oleh keluarga berkecukupan.

Kesejahteraan bagi masyarakat kalangan menengah ke bawah dapat ditunjukkan dengan adanya tingkat kehidupan masyarakat Desa Sarangmeduro yang ditandai oleh teratasinya kemiskinan yang bisa dibuktikan dengan meningkatnya kualitas tempat tinggal warga. Semula rumah dengan bangunan anyaman bambu $^{28}$, sekarang hampir semua rumah warga nelayan di Desa Sarangmeduro menggunakan bangunan batu bata agar kokoh dan tidak mudah roboh ketika datang angin kencang dan ombak besar.

Selain itu, tingkat layanan kesehatan yang semakin baik, dibuktikan dengan meningkatnya layanan kesehatan yang ada di Desa Sarangmeduro, seperti adanya 4 orang Bidan Desa, Mantri, Puskesmas yang tidak jauh jarak tempuhnya, dan layanan kesehatan lainnya.

Kesejahteraan bagi masyarakat juga dilihat dari meningkatnya tingkat pendidikan di jenjang yang lebih tinggi, dibuktikan dengan jumlah penduduk di Desa Sarangmeduro ialah 302 jiwa kaum laki-laki dan 300 jiwa perempuan yang melanjutkan pendidikan di tingkat SLTA sederajat hingga ke perguruan tinggi.

Selain itu, peningkatan kegiatan produktivitas masyarakat terjadi di sektor perdagangan, di mana di wilayah Desa Sarangmeduro para kaum perempuan mendominasi untuk berjualan rujak di depan rumah, hasil laut yang penjualannya melalui via online, dan home industry ikan asap. Aktivitas inilah yang bisa membantu masyarakat Desa Sarangmeduro untuk mencukupi kebutuhan sehari-harinya dan bisa mendongkrak tingkat kesejahteraan di Desa Sarangmeduro.

\section{KESIMPULAN}

Kontrak kerja nelayan yang dilakukan oleh warga nelayan Desa Sarangmeduro merupakan sistem kontrak kerja yang sudah turun temurun, di mana pekerjaan nelayan tersebut merupakan mayoritas mata pencaharian utama warga di Desa Sarangmeduro. Secara tidak sadar warga nelayan Desa

\footnotetext{
${ }^{28}$ Yudha, "Profesionalisme Dosen Luar Biasa (DLB) Pada Era Milenial Di UIN Sunan Ampel Surabaya: Sebuah Studi Analisis Konten."
} 
Sarangmeduro telah menerapkan kaidah-kaidah Islam. Seperti akad Muzaro'ah yang ada pada kontrak kerja nelayan tersebut dalam pembagian hasil "Maro" atau Paroan.

Keadaan warga nelayan Desa Sarangmeduro bisa dikatakan bahwa mereka hidup dengan sejahtera. Hal ini berdasarkan ketenagakerjaan yakni mereka dimudahkan dalam mencari pekerjaan yaitu terbukanya lapangan pekerjaan yang disediakan oleh para majikan kapal. Tempat tinggal yang ditempati setiap tahun terlihat ada perubahan yang semula terbuat dari anyaman bambu, sekarang rata-rata dibangun dari batu bata. Dengan adanya kontrak kerja seperti yang telah diterapkan oleh warga nelayan ini bisa membantu mendongkrak perekonomian warga nelayan Desa Sarangmeduro, serta keadaan warga yang selalu ada perkembangan.

\section{DAFTAR PUSTAKA}

Abdi, M. K., \& Febriyanti, N. (2020). Penyusunan Strategi Pemasaran Islam dalam Berwirausaha di Sektor Ekonomi Kreatif Pada Masa Pandemi Covid19. El Qist - Journal of Islamic Economics and Business, 10(2), 160-179.

Battour, M., Rahman, M. K., \& Rana, M. S. (2019). The impact of PHTPS on trip quality, trip value, satisfaction and word of mouth: Non-Muslim tourists' perspective. Journal of Islamic Marketing. https://doi.org/10.1108/JIMA-03-2019-0058

Fadilah, A., \& Makhrus, M. (2019). Pengelolaan Dana Tabarru' pada Asuransi Syariah dan Relasinya dengan Fatwa Dewan Syariah Nasional. Jurnal Hukum Ekonomi Syariah, 2(1), 87. https://doi.org/10.30595/jhes.v2i1.4416

Farwah, A. (2013). Faktor Sosial Terhadap Kesejahteraan Islami Keluarga Muslim di Kota Surabaya. Jurnal Ekonomi Dan Bisnis Airlangga (JEBA), 23(2), 154-163.

Hegnes, A. W. (2019). The map and the terroir: Adapting geographical boundaries for PDO and PGI in Norway. British Food Journal, 121(12), 3024-3042.

Heryawan, A., Fauzi, A., \& Hidayat, A. (2014). Ekonomi Pertanian, Sumberdaya Daya dan Lingkungan ( Journal of Agriculture , Resource , and Environmental Economics ) ANALISIS EKONOMI DAN KEBIJAKAN SUMBER DAYA ALAM. Analisis Ekonomi Dan Kebijakan Sumber Daya Alam Provinsi Jawa Barat, 1(3), 1-11.

Iskandar, A., \& Aqbar, K. (2019). Kedudukan Ilmu Ekonomi Islam diantara Ilmu Ekonomi dan Fikih Muamalah: Analisis Problematika Epistimologis. Nukhbatul 'Ulum: Jurnal Bidang Kajian Islam, 5(2), 88-105. https://doi.org/doi.org/10.36701/nukhbah.v5i2.77

Khan, T. (2019). Venture waqf in a circular economy. ISRA International Journal 
of Islamic Finance, 11(2), 187-205. https://doi.org/10.1108/IJIF-12-20180138

Miftakhul Jannah, D., \& Nugroho, L. (2019). Strategi Meningkatkan Eksistensi Asuransi Syariah di Indonesia. Jurnal Maneksi, 8(1), 169-176.

Raies, A. (2020). Islamic versus Conventional Fiscal policy: The effect of zakat on education and employment. Academic Journal of Interdisciplinary Studies, 9(1), 27-33. https://doi.org/10.36941/ajis-2020-0003

Rijal, A. (2018). Pengetahuan Konsumen terhadap IB Hasanah Card Bank BNI Syariah Cabang Surabaya. 1(1), 117-139.

Rohida, L. (2018). Pengaruh Era Revolusi Industri 4.0 terhadap Kompetensi Sumber Daya Manusia. Jurnal Manajemen Dan Bisnis Indonesia. https://doi.org/10.31843/jmbi.v6i1.187

Ryandono, M. N. H., \& Ridlwan, A. A. (2020). Solution for Islamic Banks Exploitation: A Criticism of Fixed-Yields Based Financing in Indonesia. AlUqud: Journal of Islamic Economics, 4(1), 48-68. https://doi.org/10.26740/al-uqud.v4n1.p48-68

Salim, \& Syahrum. (2012). Metode Penelitian Kualitatif (pp. 40-41). Citapustaka Medua.

Salisa, N. R., Aeni, I. N., \& Chamid, A. A. (2019). Analisis Faktor-faktor Penerimaan Penggunaan Sistem Keuangan Desa: Pendekatan TAM dan TPB. Ekonomi Dan Bisnis, 6(1), 34. https://doi.org/10.35590/jeb.v6i1.829

Sari, F. K., Safitri, N., \& Anggraini, W. (2019). Persepsi, Sikap dan Minat Pariwisata Halal di Daerah Istimewa Yogyakarta. Ihtifaz: Journal of Islamic Economics, Finance, and Banking, 2(2), 137. https://doi.org/10.12928/ijiefb.v2i2.857

Sudirman, S. (2012). Implementasi Nilai Total Quality Management Dalam Pengelolaan Wakaf Di Dompet Dhuafa Dan Pondok Pesantren Tebuireng. Journal de Jure, 4(2), 171-186. https://doi.org/10.18860/j-fsh.v4i2.2986

Syarifudin, Nurlailah, \& Yudha, A. T. R. C. (2020). The Allocation of Tabarru' Fund Underwriting Surplus of Iplan Sharia Product in PT. Asuransi Jiwa Generali Indonesia. Jurnal Ekonomi Syariah Teori Dan Terapan, 7(9), 18041817. https://doi.org/10.1017/CBO9781107415324.004

Yudha, A. T. R. C. (2020). Profesionalisme Dosen Luar Biasa (DLB) pada Era Milenial di UIN Sunan Ampel Surabaya: Sebuah Studi Analisis Konten. 2(Manajemen SDM), $77-86$. http://jurnalfebi.uinsby.ac.id/index.php/MANOVA/article/view/247

Zaki, I., Widiastuti, T., Yudha, A. T. R. C., Wijayanti, I., \& Mi'raj, D. A. (2020). Implementation of Islamic entrepreneurial culture in Islamic boarding schools. International Journal of Innovation, Creativity and Change, 11(11), 452-469. 
NUKHBATUL 'ULUM : Jurnal Bidang Kajian Islam

Vol. 6, No. 2 (2020) : Hal. 204-220

NUKHBATUL

ULUM

Website: https://journal.stiba.ac.id

ISSN : 2685-7537 (online); 2338-5251 (Printed)

Zustika, A. F., \& Yudha, A. T. R. C. (2020). Peer to Peer Lending System in Hifdul Maal Perspective: Evidence From he Fintech Company of Investree. Jurnal Ekonomi Syariah Teori Dan Terapan, 7(8), 1585-1597. https://doi.org/10.20473/vol7iss20208pp1584-1597 